\title{
¿ES LA LIBERTAD EL PRESUPUESTO SOBRE EL QUE SE CONSTRUYE EL EDIFICIO DE LA RESPONSABILIDAD CIVIL?*
}

\author{
IS FREEDOM THE ASSUMPTION ON WHICH CIVIL \\ LIABILITY IS BUILT?
}

\author{
Cristian Aedo BarrenA**
}

\begin{abstract}
Resumen:
El presente artículo aborda, desde las bases filosóficas constitutivas, la idea de voluntad en el ámbito de la responsabilidad extracontractual. Es en la exploración de la idea de voluntad mediante la que se alcanza el fundamento del régimen, en la libertad, que subyace a la idea de voluntad. Desde su fundamento en Aristóteles, pasando por la tradición histórica, se explica de qué modo dicha idea de voluntad se asentó, a partir de ideas kantianas (y, en definitiva, neonaturalistas), en la dogmática moderna. Se exploran, como consecuencias de dicha concepción, las diferencias de regímenes de responsabilidad, explicadas desde sus bases y la repercusión que dicha concepción ha tenido en la noción de las funciones del régimen.
\end{abstract}

Palabras claves: voluntad; libertad; culpa; funciones

\begin{abstract}
:
This article deals with the idea of free will, from the constitutive philosophical bases, in the field of tort law. When exploring in the idea of free will the basis of the regime are found and freedom underlies in the idea of free will. From its foundations in Aristotle and then referring to the historical tradition, it is explained how the idea of free will was established in modern dogmatics, based on Kantian (and, in short, neo-naturalist) ideas. As a consequence of this conception, the differences in liability regimes are explored, explaining them from their bases and the impact that such conception has had on the idea of the functions of the regime.
\end{abstract}

Keywords: free will; freedom; guilt; functions

* Este artículo forma parte del proyecto Fondecyt Regular, número 1191729, denominado "Delimitación de regímenes de responsabilidad civil. Elementos y factores a considerar para una parcial unificación", del cual el autor es investigador principal.

** Universidad Católica de la Santísima Concepción, Chile (caedo@ucsc.cl). Artículo recibido el 13 de junio de 2020, y aceptado para su publicación el 22 de julio de 2020. 


\section{LA LIBERTAD COMO PRESUPUESTO DE LA RESPONSABILIDAD CIVIL CONTRACTUAL Y AQUILIANA}

El edificio sobre el que se estructuran nuestras instituciones de contrato y de responsabilidad reposa en la idea de que el acto humano es libre. Para el contrato esta cuestión es palmaria, pero también lo es en el enfoque que sobre la voluntad tiene la responsabilidad civil. ${ }^{1}$

En este esquema de pensamiento la justicia va a ser concebida como el abstenerse de invadir la "esfera de libertad" de otro. ${ }^{2}$ De hecho, la explicación de la responsabilidad como el deber de resarcir los menoscabos como consecuencia de la irrupción ilegítima en la esfera de otro, sigue siendo el fundamento de la definición hasta nuestros días. De un lado, supone la existencia de un deber de abstención y, de otro, de un derecho subjetivo para reclamar el resarcimiento. ${ }^{3}$ Honoré nos advierte que la justicia correctiva, que es en definitiva el fundamento último de la limitación de libertad para los individuos, incluso si no hay culpa, es un principio sustantivo que tiene una base moral. ${ }^{4}$

1 Como enseña Barros (2020), p. 76: “...para que el hecho dañoso sea imputable a una persona se requiere, además de su capacidad, que su conducta sea voluntaria, esto es, que su acción u omisión le sea atribuible como acto libre". Salvador Coderch, Castiñeira y luego Díez-Picazo, de modo más general, denominan, como función de demarcación, en cuanto se trata de establecer una delimitación de fronteras entre los ámbitos de libertad de actuación y la protección de determinados bienes e intereses. SALVADOR y CASTIÑEIRA (1997), p. 103; Díez-Picazo (1999), p. 43. Para Owen (1997), p. 202, la libertad es uno de los más importantes y fundamentales valores morales que sustentan el edificio de la responsabilidad.

2 CARpintero Benítez (2000), p. 213, señala que al faltar las cosas extraindividuales desde las cuales pudiesen asentarse las relaciones jurídicas, se desarrolló esta idea de la justicia, como interpretación -según el autor- un tanto unilateral de la obra kantiana. Véase Carpintero Benítez (2004), pp. 224-228; 232-236.

3 Véase SÁnchez de la Torre (1962), pp. 12, 22 y ss. Según el autor, cuando un sujeto ejerce sus pretensiones, cuando administra sus bienes e intereses, debe hacerlo de tal forma que no embarace, limite, perjudique o dañe a la libertad e intereses de otro, cuando no respete la reciprocidad pertinente: eso es lo que llama responsabilidad jurídica. En este sentido, Filomusi (1949): 192-193. Según algunos autores, Kant puede calificarse como el epígono de la Escuela del Derecho Natural racionalista. Sobre este tema, véase especialmente el trabajo de CARPintero Benítez (1989), pp. 9-19 y Ahrens (2004), p. 48, aunque no pueden desconocerse las críticas que Kant formuló al método de la Escuela racionalista del Derecho natural. También, WeLzel (1977), pp. 175 ss.

4 Honoré (1997), p. 84. No es de extrañar que la regla del nemienm laedere haya sido calificada por RIPERT (1949), p. 198, derechamente como un principio de orden moral. Para la discusión sobre el fundamento de la responsabilidad civil, que descansa en la justicia correctiva y la distributiva, véase especialmente PINo (2013), pp. 111 ss., y PAPAYANNIS (2012), p. 80, pero especialmente PAPAYANNIS (2014), pp. 272 ss. 
También debe entenderse que el acto es libre cuando, conforme al artículo 2318, el autor del daño tiene control inicial de la situación. Como indica acertadamente San Martín:

al margen de la falta involuntaria de razón o discernimiento, el hecho de que el sujeto en realidad carezca de las aptitudes físicas o intelectuales para llevar a cabo la actividad o para prever el resultado dañino de su actuar, en principio, no es obstáculo para considerarlo en culpa, pues, desde el Derecho romano incurre en culpa quien emprende una actividad, sabiendo o debiendo saber que carecía de las aptitudes para llevarla a cabo o que por falta de atención no previó sus consecuencias, así como quien se coloca a sí mismo en la posición de no poder controlar sus propios actos. En Chile, esta última idea se encuentra recogida en el artículo 2318 CC. cuando sanciona expresamente la responsabilidad del ebrio, disposición que la doctrina ha hecho extensiva a todas las privaciones voluntarias de razón. ${ }^{5}$

Barros considera que la norma funda un juicio más amplio, en el caso que el agente, aun no teniendo dominio del hecho, haya tenido control de la causa del hecho. ${ }^{6}$

Este esquema de libertad, con fundamento en la filosofía de Aristóteles, se afianza con el esquema de la Escuela del Derecho natural racionalista, en la voluntad entendida como libertad. ${ }^{7}$ A él le precede, con todo, un intenso debate teológico que explica su triunfo.

5 SAN MARTín (2018), pp. 581-582.

6 Barros (2020), p. 80.

7 Abierto el camino para el voluntarismo y las ideas platónicas, como indica Carpintero, todos los representantes de esta corriente arrancan del estado natural del hombre, libre e igual. En realidad, como afirman AHrens (2004), pp. 16-17 y CARPintero Benítez (2000), p. 205, cada representante de la corriente enfatizó algún aspecto de dicho estado de naturaleza, a veces totalmente contradictorio, como la sociabilidad (en los casos de Pufendorf y Grocio), la felicidad (Thomasius) o la utilidad (Hennecius, llegando por esta vía hasta el utilitarismo de Bentham). En un sentido similar, Hesphana (2002), p. 153. Tal como veremos, WiEaCKER (2000), p. 232 y WiEACKER (1995), p. 214, consideran que estos diferentes fundamentos constituyen etapas diferenciadas en la construcción del iusnaturalismo racionalista. El rasgo más importante del hombre es la libertad de arbitrio, de autodeterminarse y dado que estos pensadores operaron con las categorías lógicas (especialmente el principio de no contradicción), lo que se predica en relación con uno debe ser predicado respecto de los demás. Como afirma nuevamente Carpintero, la voluntad deja de ser considerada una simple potencia humana, más o menos al servicio de la razón, y pasa a ser entendida como la totalidad de la razón. CARPINTERo Benítez (2000), pp. 212-213. 
Como indica Cassirer, avanzada la modernidad, la Ilustración combatirá vivamente el dogma del pecado original y la idea agustiniana de la corrupción natural del hombre. ${ }^{8}$ En la doctrina pelagiana, recogida por los jesuitas, el pecado, y el mal, en definitiva, se explican solamente por el libre albedrío humano. Aquí, la gracia y la redención de Cristo ayudan, pero no son indispensables. ${ }^{9}$ Esta es la idea que retomará parte importante del Iluminismo, en la construcción de la idea de naturaleza humana. La bondad humana, en cambio, cuyo principio es la libertad de acción, es la propia del hombre que no ha sido corrompido, en su estado de naturaleza, por la sociedad. ${ }^{10} \mathrm{Su}$ antecedente se encuentra en Descartes, que da como dato la libertad humana, lógicamente anterior a la duda metodológica, que debe confrontarse con la existencia de Dios, omnisciente y omnipotente y, por tanto, capaz de conocer y predeterminar los hechos del futuro. ¿Cómo compatibilizar la libertad humana con esa noción de Dios? Aquí, cabe la discusión que hemos sostenido precedentemente, irresoluble en el plano teológico.

En este punto, siguiendo a Copleston, Descartes fue ambiguo. Indica que, aunque en sus "Principios de Filosofía", evita referirse a problemas teológicos,

8 Para entender este problema adecuadamente, se debe tener presente el contexto general. Nadie mejor ha visto este problema, y su incidencia en el pensamiento jurídico europeo, que Kolakowski. En particular, el autor ilustra el conflicto del jansenismo, movimiento católico que nace en Francia especialmente, a partir del siglo XVI y el debate sobre la gracia y la libertad, entre el pelagianismo y el protestantismo. Según el autor, tanto el jansenismo como el mundo protestante veían la naturaleza humana como corrompida, siguiendo las ideas agustinianas de la caída. Del estado de perfección y unión con Dios, el hombre se apartó mediante el pecado originario. La naturaleza caída, la concupiscencia, implica que si el hombre obra mal, sigue su instinto y, si obra bien, lo hace porque la gracia que ha operado en él es irresistible. Dios ha escogido, por razones que escapan a los hombres, a quienes ha decidido salvar. Ninguna participación tiene verdaderamente la libertad en la salvación. La doctrina jansenista, que se volvió en definitiva anatema y fue condenada, se oponía a la ortodoxia jesuita, que atribuía el mérito de la salvación a la libertad humana. Para el interesante debate, véase KoLAKOwSKI (1996), pp. 20 y ss. En cuanto a las implicancias en el Derecho, se debe tener en cuenta que Domat, como parte importante de la élite jurídica de su época, era jansenista. Ello repercutió en su ética y en su posición relativa al Derecho. Para esta cuestión, remitimos a nuestro trabajo Aedo (2018c), pp. 5 y ss. Para la influencia de Domat en el proceso codificador, véase nuestro trabajo Aedo (2017a), pp. 629 y ss. Véase también Masi (1963), pp. 7-28. Para dimensión política del jansenismo y sus proyecciones, BRIAN (2013), pp. 304-308.

9 DíAz (1995-1996), p. 131.

10 CASSIRER (2013), pp. 159-168; 175-179. Es Rousseau, particularmente, quien abordará la cuestión desde la perspectiva de político-jurídico. Esta visión optimista del francés, que tanta importancia tiene en el campo del Derecho, reafirma dos cuestiones: por un lado, que la naturaleza humana es buena, pero para vivir en sociedad los individuos deben pactar y renunciar a una cuota de su libertad; en segundo lugar, que el Derecho, finalmente, reposa no en la razón, sino en la voluntad. 
defiende la libertad humana, admitiendo que, precisamente, la resolución teológica del problema trasciende el entendimiento humano (es decir que mientras se afirma la libertad se entiende que Dios pre-determina el futuro), el filósofo francés ingresó, de todos modos, a la disputa teológica, a veces favoreciendo una posición protestante de la predeterminación, otras favoreciendo las posiciones jansenistas por sobre las molinistas y, por consiguiente, jesuitas, mientras que, en otros escritos, favoreció precisamente la visión de la libertad jesuita, en cuanto indiferencia genuina para actuar bien o mal. ${ }^{11}$

Con todo, aunque no desarrolla una filosofía completa, Copleston señala que, como Santo Tomás, Descartes acepta que el fin de la vida humana es la beatitud, pero mientras para el primero la beatitud consideraba alcanzar a Dios, para el segundo significaba una tranquilidad o contento con el alma, alcanzado por el propio esfuerzo. ${ }^{12}$ Como fuere, es claro que Descartes asume, más allá de la ambivalencia sobre el problema teológico de la libertad y la gracia, una visión optimista de la naturaleza humana. Como en la filosofía clásica, el hombre obra bien y si lo hace mal lo es por error. ${ }^{13} \mathrm{Y}$, por tanto, el hombre tiene libertad para escoger entre el bien y el mal. ${ }^{14} \mathrm{Y}$ esta sería la perspectiva tarsladada a la responsabilidad civil, mantenida por la Escuela del Derecho Natural racionalista

11 Copleston (2017), t. IV, pp. 107-109. Señala el autor: "La verdad del asunto parece ser que al tratar de los temas teológicos de la controversia del libre albedrío, Descartes adoptaba soluciones más o menos improvisadas, sin una verdadera tentativa de hacerlas consecuentes".

12 Copleston (2017), t. IV, p. 112.

13 Nuevamente, con todo, se encuentra un cierto trasfondo en el dilema teológico. Como señala DíAZ (1995-1996), pp. 128-129: “Interesa señalar cómo el interés teológico del asunto condujo a un desplazamiento significativo del centro de atención, cuya consecuencia será un cambio de sentido en la preocupación filosófica. En efecto, si miramos el problema desde una perspectiva exclusivamente racional, como lo hace la filosofía, la cuestión del libre albedrío consiste en explicar la acción de la voluntad cuando parece actuar en contra de los dictados del entendimiento. Porque cuando la voluntad obra razonablemente, es decir, cuando decide hacer aquello que el entendimiento le prescribe como lo correcto, esa acción no parece difícil de explicar, ya que posee una razón suficiente. Esta se halla precisamente en lo prescrito por el entendimiento. A la pregunta ¿por qué ejecuta la voluntad dicha acción? podemos responder con claridad: porque así lo señala el entendimiento".

14 Como refiere Karmy (2008), p. 38: “Ahora bien, si el hombre contiene en potencia la posibilidad de "discernir lo verdadero de lo falso" y yace, por ello, abierto al error, significa que, en la lógica inmunitaria que hemos señalado, habría que indagar cuáles serían, según Descartes, sus causas. En efecto, después de asumir el carácter "impenetrable" de Dios y, por ende, la imposibilidad humana de conocer sus intenciones, Descartes señala que los errores dependen de dos causas, a saber: “(...) la facultad de conocer, que hay en mí, y la facultad de elegir, o sea mi libre albedrío; esto es, mi entendimiento y mi voluntad” (p. 166). Así, dice Descartes, el hombre tiene, ante todo, "libre albedrío", precisamente porque no solo puede conocer, sino porque puede "elegir" lo bueno de lo malo". 
y adaptada por la Ilustración. Las bases kantianas de la responsabilidad corresponden, en definitiva, a este esquema. ${ }^{15}$

Pasemos ahora cómo esta idea de libertad se proyecta en la configuración de la voluntad en la responsabilidad civil contractual y aquiliana que, aunque se proyecta de distinto modo, se funda en esta misma idea de libertad que acabamos de analizar.

\section{LA MANIFESTACIÓN DE VOLUNTAD EN LOS CONTRATOS Y EN LA RESPONSABILIDAD AQUILIANA: UNA DUALIDAD HISTÓRICA Y DOGMÁTICA}

\subsection{La idea de voluntad contractual en la codificación y su base en el pensamiento aristotélico}

¿Cuándo estamos en presencia de voluntad, de un acto humano, en la responsabilidad civil? Aunque la doctrina le ha prestado poca atención, el esquema de la voluntad, en los delitos y cuasidelitos, permite responder la pregunta que nos planteamos en este artículo y, por su intermedio, aproximarnos, inicialmente, a la cuestión de la libertad (que subyace a la voluntad), y, a las funciones del régimen. Por eso, conviene detenerse en estos dos presupuestos sobre los que se opera: la manifestación de voluntad y la idea que subyace de causalidad en ella. ${ }^{16}$ Descubriendo sus fundamentos podemos, como se ha dicho, analizar el problema de la libertad en la responsabilidad civil, en un sistema como el chileno.

Como veremos en breve, la idea de voluntad en la responsabilidad aquiliana dista de la idea de voluntad, tal como esta se predica en la teoría del acto jurídico.

15 Véase, para esta cuestión, especialmente a partir del pensamiento de Weinrib, a WRIGHT (1992), pp. 644-665.

16 Aunque es un problema ajeno al que queremos abordar, se debe tener presente que, aunque con bases filosóficas diversas, el mundo romano, con la tradición jurídica subsecuente y la modernidad, con el énfasis de las ideas platónicas y el predominio de las matemáticas en la comprensión del mundo, operan sobre la base de una causalidad material, estructurada sobre un mundo de escenario inmutable, acorde a leyes, también inmutables, lo que se traduce en una distancia sujeto/objeto en la determinación de los procesos causales. Para la aproximación de las ciencias modernas a las matemáticas y las ideas platónicas, como afirma Bello Reguera (1993), p. XXVI. Véase Alpa y Bessone (1976), p. 280. Para la tradición codificada, por todos, RIPERT Y Boulagner (1965), pp. 106; 110. 
Toda la doctrina del acto jurídico concibe la voluntad como aquella que ordena la libertad hacia un fin. ${ }^{17}$ Es decir, se trata de la idea aristotélica de voluntad.

En efecto, siguiendo en esta materia a Gordley, en relación con los contratos, partiendo del análisis en el artículo 1134 del Code Napoléon, que es considerado el mecanismo mediante el cual se consagró la autonomía de la voluntad, Gordley considera que los redactores no hicieron más que incorporar las ideas de Domat y Pothier, de los iusnaturalistas, que a su vez las recogieron de la segunda escolástica y esta a su vez de las ideas de Tomás de Aquino, quien habría elaborado sus doctrinas de la propiedad y el contrato tomando como base el pensamiento de Aristóteles. Así, tratándose de la propiedad, ya con Aristóteles se había desarrollado la doctrina de la propiedad individual frente a la comunitaria, pero además dicha definición -la del artículo 544-, así como el resto del articulado, se centraba en las limitaciones a la propiedad más que en su aspecto individualista. En materia de contratos, como señala gráficamente Gordley, el artículo 1134 prescribe que el contrato es una ley para las partes, pero en ningún lugar, por el contrario, se establece el principio de autonomía de la voluntad. Nuevamente, las bases del libre pacto generador del contrato habrían sido tomadas de Tomás de Aquino y transportadas hasta los iusnaturalistas. Gordley destaca que la norma se refiere a la "naturaleza" de los contratos y que de dicha naturaleza emanan reglas conformes a la "equidad". ${ }^{18}$

Ciertamente, Gordley lleva razón, aunque no puede dejar de anotarse que, en esta materia, como ocurre con la Escuela de Derecho Natural racionalista que le precede y le da forma, el Code representa una verdadera simbiosis entre la continuidad y la ruptura. ${ }^{19}$

17 Para esta cuestión, véase De Castro y Bravo (1967), pp. 57-58, quien, citando la autoridad de Tomás de Aquino, dice: “...ya que el negocio jurídico, como instrumento de la libertad humana, tiene su raíz en la voluntad (quod radix libertatis est voluntas)". Y agrega: "La voluntad se mueve por la vis cognoscitiva (nihil volitum nisi praecognitum) y por la vis appetitiva (el deseo, velleitas). Conocidas (tener conciencia) y, en su caso, pesadas ("juicio", "consultado", "deliberarlo") posibilidades y fines, se llega a la decisión ("electio"; preferencia respecto de fines y medios posibles). Esta se concreta en la intención o propósito con el que se dice o hace algo (conducta del declarante). Para que dicha voluntad alcance significado jurídico, no basta con que exista anteriormente (cogitationis poenam nemo patitur), sino que se requiere sea exteriorizada o manifestada (de manifestis tantummodo iudicare, Inocencio III)". Para el Derecho chileno, Vial del Río (2004), p. 22.

18 Gordley (1994), pp. 459-479; 483-505. Véase también, GordLEy (1992), especialmente pp. 35 y ss. El autor explica cómo los juristas medievales adoptaron, desde los textos romanos, la tradición filosófica de Aristóteles, recogida, a su vez, por Tomás de Aquino.

19 Siguiendo a Watson (1986), p. 29, el Derecho romano ha mostrado ser en la experiencia un sistema extremadamente adaptable, operando en todo tipo de realidades regionales, 


\subsection{La idea de voluntad en la responsabilidad extracontractual, ¿tiene base aristotélica?}

\subsubsection{La idea en la dogmática}

En la responsabilidad civil, como decimos, la idea de voluntad es distinta a la que se postula en la teoría contractual. Veamos algunos ejemplos de tratamiento dogmático, para advertir la diferencia tanto en la doctrina comparada como en la chilena.

Bueres explica que la manifestación de voluntad humana, voluntaria e involuntaria, comprende los actos instintivos y habituales y fuera de él se encuentran solamente los actos reflejos, estados de inconsciencia total, o los que resultan de una fuerza irresistible. ${ }^{20} \mathrm{Y}$ para Santos Briz:

...el concepto jurídico de la acción es distinto que el filosófico, que solo comprende el obrar querido. Aquel comprende, además, la producción de un resultado mediante un movimiento corporal o inconsciente, en tanto se dé la posibilidad de un control de la conciencia junto a la dirección de la voluntad (...) el agente ha de responder jurídicamente también de aquellas consecuencias de su actuación relacionadas con sus acciones que no ha previsto y aún las que no ha querido, pero con las cuales, según la previsión humana, debió contar y que por ello han de considerarse controlables por él. ${ }^{21}$

En el mismo sentido, Antunes Varela indica que cuando se alude a un hecho voluntario del agente, no se pretende restringir los hechos humanos relevantes en materia de responsabilidad a los actos queridos, es decir, aquellos casos en que el agente tenga prefigurados mentalmente los efectos del acto. Por el contrario, la responsabilidad surge cuando no existe ninguna representación mental o inclusive tratándose de actos dañosos practicados por distracción o falta de autodominio normal. ${ }^{22}$

Entre los autores chilenos se encuentra el mismo acuerdo. Como Rodríguez Grez, para quien la circunstancia que deba tratarse de un hecho (acción u omisión)

culturales, sociales, políticas y religiosas. Tratándose del Code, la racionalización de las instituciones romanas y de la tradición francesa recibirá, en efecto, su último impulso en Portalis.

20 Bueres (1996), pp. 42-43. Con todo, también en materia de negocio jurídico, se considera que la voluntad deja de ser tal si el sujeto se ve privado o disminuido en sus capacidades mentales y/o físicas. Véase Flume (1998), p. 76.

21 Santos Briz (1993), pp. 26-27. Véase también, DíEz-Picazo (1999), p. 287.

22 Antunes Varela (1996), p. 547. 
del hombre es una cuestión objetiva que escapa del análisis de la voluntariedad, la que debe quedar entregada a la imputabilidad o del elemento subjetivo. ${ }^{23}$ Corral, que también denomina a este elemento acto humano, explica que debe tratarse de un hecho voluntario, quedando excluidos los estados transitorios de pérdida de la razón, como el sonambulismo, la hipnosis o la violencia física o moral. ${ }^{24}$

Como hemos destacado en otra oportunidad, estas ideas en relación con la conducta humana han sido tomadas de la dogmática penal, particularmente de las concepciones causalista y neoclásica del delito. ${ }^{25}$

\subsection{La base de la construcción en la distinción acto voluntario e involuntario de Aristóteles}

Con todo, no puede desconocerse tampoco aquí, en el ámbito aquiliano, una influencia decisiva del pensamiento de Aristóteles. Para efectos de este trabajo, puede decirse lo siguiente. Tanto en la filosofía de Sócrates, como la de Platón, así como Aristóteles, la idea de la voluntad entronca con el conocimiento, de modo que si una persona obra mal moralmente lo hace, en buena medida, por desconocimiento, dado que el ejercicio de la voluntad es, especialmente en

23 Rodríguez Grez (1999), p. 124.

24 Corral (2004), pp. 112, 113-114.

25 NÁQUiRa (1998), p. 11: Al respecto, Náquira indica: “Influenciados por el positivismo naturalista y como reacción a la teoría hegeliana de la imputación, Beling y Von Lizt postulan que la acción debería ser conceptualizada como: "movimiento corporal voluntario que causa una modificación en el mundo exterior perceptible por los sentidos". El carácter "voluntario" del movimiento corporal se reduce y limita, única y exclusivamente, a afirmar la concurrencia de una simple y mera "voluntad de causar"; en otras palabras, a comprobar la existencia de una inervación muscular voluntaria". La teoría causalista recibió los aportes posteriores de la concepción causal neoclásica del delito, defendidas por Mezger, Mayer, entre otros, conforme a la cual la acción, considerada como simple inervación muscular, pasa a ser concebida en términos valorativos como conducta humana. Como Náquira: "Bajo esta doctrina, la voluntad no es considerada única y exclusivamente en una dimensión mecánico-causal: motor y fuerza de movimientos musculares, sino como portadora, además, de un cierto y determinado "sentido social": de una idea, un propósito o una finalidad que anima el actuar humano (...) A pesar de haber reconocido este nuevo enfoque causal que la acción suponía un factor objetivo-externo: lo voluntario-causal, y un factor subjetivo-interno: lo voluntario-final, en definitiva esta doctrina persistió en mantener la división entre la voluntad como fuerza causal y el contenido de la voluntad como fuerza final y, por ende, en afirmar que la acción se agotaba en lo objetivo-externo: lo voluntario causal, relegando lo subjetivo-interno, al igual como lo hiciera la doctrina antecesora, al terreno de la culpabilidad". 
Aristóteles, un hábito más que una disposición. ${ }^{26}$ Debe advetirse, en cualquier caso, siguiendo a Dilhe, que las expresiones voluntario e involuntario no fueron conocidas por los griegos. Por un lado, Dihle demuestra que en el pensamiento griego la idea de la voluntad no fue desarrollada (ni siquiera en materias legales). Los griegos, en su concepto, explicaban el pensamiento con una lectura intelectualista: las decisiones dependían o del intelecto o de las pasiones: ambas fuerzas potenciaban o bien bloqueaban la decisión, en uno u otro sentido. Por otro lado, Dihle explica el desarrollo de la doctrina de la voluntad, especialmente de la mano de San Agustín. ${ }^{27}$

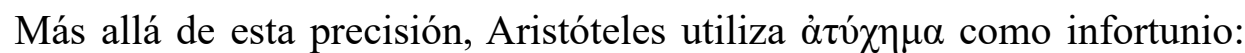
"Pues bien, cuando el daño se produce de un modo imprevisible, es un infortunio"

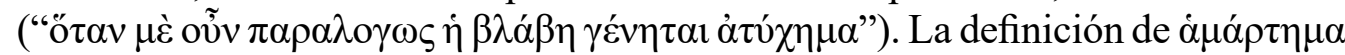
es más compleja, pues según Aristóteles cuando el daño: “...no se produce de un modo imprevisible, pero sí sin malicia, es una equivocación” ("őtav $\delta \varepsilon \bar{\varepsilon} \mu \eta ́$

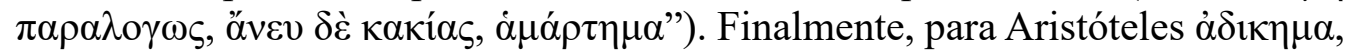
se plantea si: "...se obra a sabiendas pero no de un modo deliberado, se comete

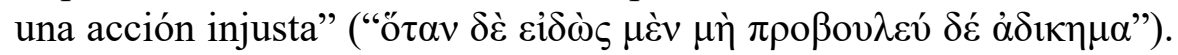

A partir de esta diferenciación, se ha propuesto la conexión de la culpa con

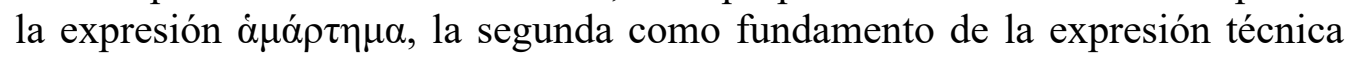
forjada a la luz de la lex Aquilia. De esta cuestión nos hemos ocupado en otro lugar. ${ }^{28}$ Lo interesante es que dicha conexión, es decir, aquella que vincula la culpa con los actos voluntarios e involuntarios en Aristóteles, se mantuvo firme en la tradición teológica tomasiana y en la tradición jurídica medieval e incluso humanista, fundada a su vez en la filosofía medieval de Aristóteles.

Masi advierte que todos los jesuitas de la segunda escolástica, en definitiva, se fundamentan en Santo Tomás, concretamente en un pasaje de la Suma Teología, I, II, C. 71, art. 6, ad. 5, texto en el que el aquinatense sostiene que el pecado es considerado por el filósofo en cuanto contrario a la razón y por el teólogo en cuanto ofensa a Dios. ${ }^{29}$ Pero Santo Tomás no solo tiene importancia

26 Milo (1996), pp. 67-70; Adkins (1960), pp. 326 y ss. Vicol (1973), pp. 317-329. Como indica Trueba (2004), p. 111, uno de los criterios en Aristóteles para la adcripción legal de los crímenes fue la ignorancia. Según la autora, en Ética de Nicómaco: “...Aristóteles considera que la ignorancia desempeña un papel en el curso de determinadas acciones y en esa medida puede servir de base para disculpar o exonerar de responsabilidad al agente".

27 Dihle (1982), pp. 21 y ss.; 141 y ss.

28 Aedo (2013), pp. 44 y ss.

29 Masi (1963), p. 8; quien advierte, sin embargo, que si bien es cierto Santo Tomás efectivamente distingue los dos aspectos de la moralidad (humano y divino), no separó com- 
porque en él puedan encontrarse las huellas de la doctrina del pecado filosófico, que permite a nuestro juicio la separación estricta de los ámbitos de la moral humana y divina, la secularización del Derecho y la construcción de una cláusula general de responsabilidad. ${ }^{30}$ En él se puede reconocer un concepto más objetivo de la culpa, en el pasaje de la Suma Teológica, contenido en II-II, q.64 art. 8 ad1, e ibidem ad2, en el que Santo Tomás distingue, a propósito del homicidio, entre conductas ilícitas y lícitas, jugando un papel la culpa solo en los supuestos de conductas lícitas.

pletamente ambos aspectos, pues el racional no podía subsistir sin el divino. En efecto, en DE Aquino (1963), p. 455, nos dice: "peccatum significat malu hominis actum, ut ex dictis patet (a.1; q. 21 a.1). Sed malum hominis est contra rationem esse, ut Dionysius dict, 4. Cap. De div. Nom. Ergo potius debuit dici quod peccatum sit contra rationem, quam quod peccatum sit contra legem aeternam".

30 El Código Civil chileno, como todos los de la familia continental, consagra una regla general de reparación de daños, como sabemos, en el artículo 2314, bajo la idea histórica de los delitos y cuasidelitos, cuyo origen se encuentra en la lex Aquilia. Hasta el iusnaturalismo racionalista no se encontrará un régimen general de responsabilidad, cuyas primeras bases fueron establecidas por Grocio, con claros precedentes en la segunda escolástica española. En efecto, en el caso de nuestro Código, Bello, en sus Instituciones de Derecho Romano, tratando la lex Aquilia, ya había distinguido entre delito y cuasidelito, según si el ilícito se causaba con dolo o culpa, respectivamente. En efecto, en el título V, "De la lei Aquilia", del Libro IV, se lee: "El daño injurioso (damnum injuria datum) que se vindica por la ley Aquilia, es cualquiera disminución de nuestro patrimonio irrogada contra derecho y por un hombre libre. Porque si el siervo (y antiguamente el hijo de familia) causa el daño, este se llama noxia y si lo causaba un cuadrúpedo pauperies. Se da contra el dañador la acción de la ley Aquilia no solo por dolo sino por culpa aun levísima; por lo que esta ley pertenece no solo a los delitos, sino a los cuasidelitos". Tratando los cuasidelitos, en el título V, Bello dice: "Los cuasidelitos son hechos ilícitos cometidos sin dolo y con culpa”. Bello (1981), p. 174. Bello, en efecto, cita como fuentes de su tratamiento, el D. 9, 2, 27, 5, que trata el tercer capítulo -considerado la regla general en materia de lex Aquilia-, y el título XV, de la Partida $7^{\mathrm{a}}$, pero en ninguno de ellos la distinción entre delitos y cuasidelitos aparece del modo que se propone en el curso de Derecho romano del redactor. Estas ideas parecen provenir de Heinecio, que tuvo gran influencia en el pensamiento de Bello, que las habría adoptado, a su vez, de una tradición anterior. En efecto, por ejemplo, si se repasa la obra de Heinecio, Elementa iuris civile secundum ordinem Institutionum, trata la materia en el Libro IV, título I "De obligationubus quae ex delicto nascuntur". Dice Heinecio que delito es: "Est verum delictum factum illicitum, sponte admissum, quo quis ad reflitutionem, si fieri possit, ad poenam obligatur (...) Est porro vel verum delictum, vel quasi delictum. Illud ex dolo malo; hoc ex culpa fine dolo admittitur" ("El delito pues o es verdadero, o cuasidelito. Aquel nace de dolo malo, este de culpa"). Heineccio (1787), p. 324. Para la traducción al castellano, puede consultarse la obra Heineccio (1829), p. 273. En cuanto a Vinni, véase Vinni (1755), pp. 811-812. Para el origen y desarrollo de la lex Aquilia, véase Aedo (2009), pp. 311-337 y Aedo (2011), pp. 3-30. Para la evolución del régimen, hasta la Codificación, Aedo (2018), pp. 15-223. 
Es muy interesante la reflexión que nos ofrece Santo Tomás que, en estas materias, como él mismo indica, sigue los razonamientos de Aristóteles. Esta misma conclusión sigue Santo Tomás, según quien las cosas que denomina fortuitas absolutas, en las que no interviene voluntad alguna, no pueden dar lugar a la responsabilidad. Por el contrario, en C. 64, art. 8, resp., nos dice:

...sucede, a veces, que algo que no se quiere o intenta en el acto y por sí mismo, está en la voluntad o en la intención accidentalmente, en cuanto se llama causa accidental la que remueve los obstáculos. Por consiguiente, el que no evita las causas de las que se sigue el homicidio si debe evitarlas, será culpable en cierto modo de homicidio voluntario. ${ }^{31}$

Precisamente, en este punto se encuentra el aspecto central de la argumentación tomasiana, pues en el fundamento de la atribución de responsabilidad coloca la situación inicial de control, de la que derivaría la posibilidad de evitar el menoscabo para otro. Esto es muy significativo, pero antes añadamos que sobre este principio Santo Tomás distinguirá diversos casos, según el dañante se encuentre en una situación ilícita o lícita (requiriendo la culpa solo en la segunda hipótesis). De acuerdo con C. 64, art. 8, resp.:

Y esto sucede de dos maneras: primera, cuando alguien, ocupándose en cosas ilícitas que debía evitar, comete homicidio; segunda, cuando no pone de su parte el debido cuidado. Por esto, con arreglo al derecho, si uno se ocupa en cosas lícitas poniendo el debido cuidado, y, sin embargo, de su actuación se sigue la muerte de un hombre, no es culpable de homicidio. Más si hubiere empleado en cosas lícitas, pero sin poner la diligencia debida, no evita el reato de homicidio si de su operación se sigue la muerte de un hombre. ${ }^{32}$

Ahora bien, la explicación de Santo Tomás nos parece extremadamente relevante a los efectos de nuestra investigación, porque de ella se pueden esta-

31 De Aquino (1990), p. 538. Según el texto el latín, De Aquino (1963), p. 419: “Contingit tamen id quod non est actu et per se volitum vel intentum, secundum quod causa per accidens volitum et intentum, secundum quod causa per accidens dicitur removens prohibens. Unde ille qui non removet ea ex quibus sequitur homicidium, si debeat removere, erit quodammodo homicidium voluntarium".

32 De Aquino (1990), p. 538. De acuerdo con el texto en latín, De Aquino (1963), p. 419: "Hoc autem contingit dupliciter: uno modo, quando dans operam rebus illicitis, quas vitare debebat, homicidium incurrit; alio modo, quando non adhibet debitam sollicitudinem. Et ideo secundum iura, si aliquis det operam rei licitae, debitam diligentiam adhibens, et ex hoc homicidium sequatur, non incurrit homicidii reatum: si vero det operam rei illicitae, vel etiam det operam rei licitae non adhibens diligentiam debitam, non evadit homicidii reatum si ex eius opere mors hominis consequatur". 
blecer algunas vinculaciones importantes. La primera es que nos muestra que la culpa tiene un contenido y desempeña un papel similar al Derecho romano, en el que la culpa jugó un rol importantísimo, como mecanismo de ampliación de la lex Aquilia, precisamente en aquellos casos en los que la conducta, a pesar de ser lícita, el sujeto se encontraba en posición de control y, por consiguiente, de evitación. En segundo lugar, en lo que respecta al contenido, Santo Tomás coloca en el fundamento de la culpa el control de la situación, desde donde deriva la posibilidad de evitación de un daño, cuando un sujeto está colocado en una posición de deber. Ambas cuestiones quedan muy bien representadas en el pasaje del D. 9, 2, 31 pr. ${ }^{33}$

Y, dado que Santo Tomás se fundamenta a su vez en la diferenciación entre actos voluntarios e involuntarios de Aristóteles (y a su vez se repara en la coincidencia entre el planteamiento del aquinatense y los textos romanos), podría pensarse que aun cuando no hay plena equivalencia entre el concepto romano de la culpa y los términos griegos que directa o indirectamente se vinculan con él, especialmente $\alpha \mu \alpha ́ \rho \tau \eta \mu \alpha$, no puede dudarse de la influencia del pensamiento Aristotélico en el romano. Es posible sostener que el pensamiento aristotélico sirvió como base para la construcción de la culpa, como situación inicial de control, lo que permite incorporar en los supuestos de culpa estricta, por ejemplo, las hipótesis de falta o ausencia de conocimientos técnicos para desarrollar una actividad; o bien, permite comprender por qué un sujeto que se encuentra en estado de ebriedad debe responder de los perjuicios que causa. ${ }^{34}$

33 Como indica Engelmann (1965), pp. 17-18, los comentaristas recogieron la tradición del Derecho romano, para definir el comportamiento culpable como la posibilidad de prever una consecuencia dañosa, la desviación de un comportamiento debido, al punto de encontrarse en situación de evitar un comportamiento desviado. Para las funciones de la culpa en la lex Aquilia, véase AEDo (2014a), pp. 51 y ss.

34 Como enseña HruchKa (2005), pp. 57; 63-64, estas dos formas puestas en terminología moderna pueden denominarse, respectivamente, imputación ordinaria e imputación extraordinaria: en la primera, la persona en cuestión, en el momento decisivo, está en condiciones de evitar la producción de un suceso o de realizar la acción en cuestión; en la extraordinaria, en cambio, en el momento decisivo la persona no está en condiciones de evitar la producción del suceso o de realizar la acción en cuestión, pero puede reprochársele precisamente que se encuentre en esta situación de imposibilidad. Es decir, hay imputación ordinaria si el agente era libre originariamente y mantuvo la libertad después, como si no siendo libre originariamente, posteriormente lo es y puede asumir el control de la situación. La imputación extraordinaria, en cambio, se configura cuando la acción no fue libre en el momento de provocar el evento dañoso, pero sí en su origen, en cuyo caso se le denomina actio libera in sua causa. Si en ningún momento existía libertad en el desarrollo de la conducta, es decir, tanto si al comienzo como en la afectación del bien no la hay, no existe libertad in se y el hecho no puede ser imputado. 
Por ello, Gordley lleva razón cuando afirma que el principio de la responsabilidad fundado en la culpa no proviene de una teoría nueva, ni individualista. Nuevamente, considera que las bases de la teoría son puestas por Aristóteles, quien distinguió los actos voluntarios de los involuntarios. Según el autor, es Santo Tomás quien, tomando al hombre como ser racional, consagra el principio de que el hombre solo es responsable por su culpa, el cual fue abrazado por la segunda escolástica (particularmente Molina y Lessius) y luego por los representantes de la Escuela del Derecho Natural. ${ }^{35}$

Del mismo modo, uno podría elevar la mirada y buscar hasta dónde alcanzaron las influencias del aquinatense -y, por su intermedio, aristotélicas-. En principio, la segunda escolástica mantuvo la enseñanza de Santo Tomás sobre estas materias. Podemos destacar, por ejemplo, las enseñanzas de Domingo de Soto. En su libro De Iustitia et de Iure, precisamente a propósito del tratamiento del homicidio, se pueden ver reflejadas las ideas tomasianas. Según de Soto:

Nadie que obra lícitamente y sin torcida intención, aunque de su acción se siga un homicidio, incurre por ello en responsabilidad, con tal que de su parte haya puesto la debida diligencia, para no causar ningún daño (...) Tercera conclusión: Si uno hace una cosa ilícita, o practicando una lícita no pone el debido cuidado, no queda exento de culpabilidad en el homicidio que de semejantes actos se siguiere. Prueba de la conclusión. Sucede que lo que no es querido, ni intentado en acto de por sí, es querido e intentado accidentalmente, por cuanto no evita lo que o podía, o tenía obligación de evitar; ya que la causa que guiaba lo que lo prohíbe se considera accidental. De donde se sigue que quien no evita o impide la causa o acción que tenía obligación de evitar e impedir, se haga reo de homicidio, si se sigue de ellas. Y esto puede ocurrir de dos maneras. Una cuando uno ejecuta acciones ilícitas, que tenía obligación de evitar; y otra cuando, al ejecutar actos lícitos, no pone el debido cuidado; de lo cual se sigue el homicidio. ${ }^{36}$

\footnotetext{
35 Gordley (1994), pp. 479-480.
}

36 De Soto (1968), t. III, L. V, c. I, art. IX, p. 406. De acuerdo con el texto en latín: "Secunda conclusio. Nemo dans operam rei licita, neq; finistram habens intentionem, dum modo debitam adhibuerit diligentia ne noceat, quis ex actione sua fecuat homicidium, reatum illius incurrit. Conclusio haec praecedentis appendix est \& corollaria (...) Tertia conclusio. Si quis dat operam rei illecite, vel das operam rei licita debita non adhibet diligentiam, non est a reatu homicidii immunis, q ex eiusmodi actioni fuerit subsequutu. Probatur conclusio. Contingidit quod actu per se neq; volitum est neq; intentum, per accidens esse volitum atq; intentum: quatenus id non impedit quod impediretum poterat tum etia debebat. Nam causa quae prohibes remouver, dicitur accidetaria. Quo fit ut qui causam vel actione non remouet atq; impedit qua tollere debebat, si sequatur homicidiu, reus eius coflituatur. Hoc aute fit dupliter. Uno modo quando opera nauat rebus illicitus, qs vitare debebat; altero vero qn va cans rebús licitis diligentiam no ad hibet: ex cuius contraria negligentia subsequitur homicidium". 
Más adelante, agrega esta muy interesante consideración:

La segunda manera de imputarse el homicidio casual, es por causa de negligencia, la cual si no constituye culpa, tampoco es causa de irregularidad como consta por los capítulos más arriba citados, con los cuales dimos apoyo a la segunda conclusión de Santo Tomás. Porque aunque se pueda incurrir en irregularidad sin culpa alguna, como se ve claramente en el juez, sin embargo debe de ser voluntario, como hemos dicho; y cuando la negligencia carece de toda culpa, su efecto no se considera voluntario, ya que lo involuntario en aquellas cosas que son causadas accidentalmente, consiste, como se dijo, en omitir lo que se debía hacer. ${ }^{37}$

Ahora bien, se puede apreciar en Soto, que desde luego profundiza el punto de vista tomasiano, una clara distinción entre negligencia y culpa, en el entendido que la primera no agota la segunda. Desde esta perspectiva, puede verse cómo la culpa es apreciada como un reproche a una conducta en sí misma considerada, enfatizando tal reproche en el comportamiento.

Pero analizado ahora el pensamiento jurídico, de glosadores y comentaristas, superada la idea de la culpa como nomen generale, siguiendo a Badosa, la culpa estricta incorporó sus dos elementos diferenciadores: el deber de diligencia y la involuntariedad del acto, comprendidas ahora como equivalentes. Como afirma el autor: "La involuntariedad es, ciertamente, no dolo, pero también es imputación al deudor". Y agrega: "En esta imputación se halla la raíz de la eficacia de la culpa como fuente de responsabilidad del sujeto". Se pregunta, de este modo, Badosa, por qué razón la imputación consistente en la involuntariedad es castigada con la responsabilidad. El punto de vista del autor, que recoge de la reconstrucción histórica del ius commune, ciertamente coincide con nuestra perspectiva de la culpa:

El reproche en la culpa se funda en que la infracción o ilicitud cometida, si bien no voluntaria, era evitable por el deudor. Expresiones como negligencia, desidia, falta de atención o cuidado, utilizadas para describir la posición subjetiva del deudor, son otros tantos nombres

37 De Soto (1968), t. III, L. V, C. I, art. IX, p. 409. Según el texto en latín: "Secundus modusquo causale homicidiu imputatur est negligentia: quae quide si absq, vlla fuerit culpa, nulla est irregularitatis causa: vt capitulis supra citatis habetur: quibus secunda conclusionem: diui Thomae sussulsimus. Na etsi irregularitas citra culpa incurrit, vt paret inseculariiu dice, debet tamen vt diximus, ese voluntaria: \& vbi negligentia extra omnem est culpa, effectus non censetur voluntarius: quado quidem involutariu, vt dictum est in His que caue sunt per accidens, non est nisi vbi homo id facere omittit quod facere debuit". 
para el mismo fenómeno: estaba en manos del deudor el que la infracción no se hubiera cometido. ${ }^{38}$

Esta fuerte tradición se mantuvo incluso en el humanismo, en autores como Cuyacio, que vincula la impericia y la culpa con $\alpha \mu \alpha ́ \rho \tau \eta \mu \alpha$ aristotélico. En efecto, dice Cuyacio: "Imperitia quidem ipse non est maleficium, nec enim quod ignarus sum juris, aut medinice, ideirco versor in maleficio, sed et quod quis imperite facit, quam-

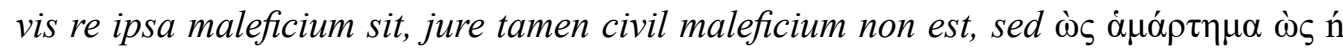

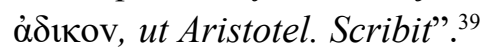

A pesar de que no puede dudarse el fondo de la filosofía de Aristóteles en nuestras ideas de responsabilidad extracontractual, lo cierto es que dicha conexión se puede hacer con la culpa y no, estrictamente, con la manifestación de voluntad, como se ha entendido en el plano dogmático. Se trataría entonces de pensar en un acto culpable, más que solo en el acto, pero esta noción correspondería a lo que Aristóteles concibe como acto involuntario y no, como hemos dicho, con la expresión de voluntad del contrato. Pero aquí es importante diferenciar, siguiendo a Hart, la inadvertencia de la negligencia, entendida en el lenguaje técnico que empleamos, pues la simple inadvertencia corresponde al juicio ordinario que hacemos de quien desatiende una actividad y provoca un resultado, como una operación psicológica, de quien, por el contrario, se le reprocha por no cumplir con el estándar exigido para el desarrollo de una actividad. ${ }^{40}$

Veamos, finalmente, qué consecuencias pueden extraerse de esta diversa aproximación a los fundamentos del régimen.

38 BAdOSA (1987), pp. 671; 685.

39 Cuyacio (1585), Cap. IV, p. 1231.

40 HaRt (2019), pp. 152-154. Es por lo demás, el concepto de culpa mayoritariamente aceptado en la dogmática chilena y comparada y, a nuestro juicio, es el concepto recogido de la tradición histórica. Para el concepto de culpa y su fuente histórica, AEdo (2018a), pp. 329 y ss. Véase también Honoré (2002), pp. 16-21. Según el autor, de acuerdo con el principio de la culpa, una persona es responsable solo cuando pudo haber controlado la situación en la que se encuentra, pero falla en ello. Solo si una persona pudo haber actuado de otra forma es moralmente responsable y se requiere un reproche para su acción y, en el caso de la negligencia, él es responsable solo cuando podría haber actuado de acuerdo con el estándar requerido. La culpa no se traduce solo en una falta de carácter, sino en la necesidad de remediar dichas faltas para evitar un daño a otro. Según Honoré, Gayo fue el primero en desarrollar una teoría de la culpa, de origen jurídico, no filosófico y cita el conocido caso del muletero, en D. 9, 2, 8, 1, en el que hace responsable al muletero porque sabía o debía haber conocido su incompetencia antes de decidir manejar las mulas. Entonces el muletero o conoció su propia incompetencia o fue incapaz de verla -a sus propios ojos él era un hábil conductor-, pudiendo haberla visto. La culpa, así, puede servir para justificar un sistema en el que hay falla en las competencias. 


\section{LAS CONSECUENCIAS DE LAS DIVERSAS APROXIMACIONES A LA NOCIÓN DE VOLUNTAD: DISTINCIÓN DE LOS REGÍMENES Y EL PROBLEMA DE LAS FUNCIONES}

\subsection{Distinción de regímenes a partir de la idea de voluntad: una distinta ponderación de riesgos}

El esquema de la voluntad, como se presenta en la responsabilidad civil, incide, en primer lugar, en la distinción de regímenes. Si en la responsabilidad contractual estamos frente a la noción clásica de voluntad, que reposa, a su vez, en la idea de libertad que hemos analizado, el contrato importa una relativa igualdad, al menos formal de las partes, que supone un igual acceso a la información y a las condiciones de contratación. ${ }^{41}$ Ello justifica en las codificaciones, incluso en aquellas que han introducido recientes reformas, la mantención de los principios de la autonomía de la voluntad, la libertad contractual y del pacta sunt servanda ${ }^{42}$

La existencia de un contrato, por consiguiente, es fundamental para que el régimen de responsabilidad contractual se configure. ${ }^{43}$ Como señala Barros, la fundamental distinción entre los regímenes de responsabilidad se encuentra en la voluntad de obligarse frente al hecho ilícito como fuente obligacional. En efecto, la responsabilidad contractual viene precedida por una relación que, sometida a los controles de eficiencia y eficacia de la voluntad, constituye un régimen

41 Véase, para esta cuestión, BERNAD (2019), pp. 16-21 y BuSNELLI (2005), pp. 535-537. Como afirma MAiorca (1981), pp. 253-254, la afirmación del Código Civil italiano de 1942 de que el contrato es una ley para las partes (fórmula similar a la empleada por el francés o el chileno), es una expresión solemne para expresar que el contrato es un instrumento de autorregulación de los intereses de las partes.

42 Véase, por ejemplo, para la reforma al Código Civil francés, TAISnE (2019), pp. 2728. Para el Derecho Europeo, véase el análisis de Schulze (2017), pp. 117-120 y con una perspectiva comparada europea muy amplia, ZIMMERMANN (2019), pp. 93-104. En el derecho inglés, en cambio, la voluntad solo cumple un papel subsidiario, en la medida que ella debe traducirse en la expresión de su promesa en un deed, o que se haga a cambio de una consideration. Véase CARTWRIGHT (2019), pp. 226-227. Ello no quiere decir que no exista una tendencia a releer las normas contractuales que persigan el amparo de la parte contratante más débil, más allá de las variaciones económicas del contrato, sino también en el desequilibrio en la generación del contrato. Véase, sobre esta materia, BARCELlONA (2001), pp. 306-310; 321-322; Gómez (2018), pp. 30-33; 160-170.

43 Véase Bianca (2018), pp. 120-121; 263 y ss.; Di MaJo (2005b), pp. 246 y ss.; DI Majo (2006), pp. 76-77; Fernández (2012), pp. 201-202; Jordano Fraga (1987), p. 31; Morales Moreno (2006), pp. 56-57; Pantaleón (2010), pp. 228-229. 
diseñado, delineado por las partes ${ }^{44}$ por consiguiente, $\mathrm{y}$ a diferencia del sistema de responsabilidad aquiliano, son las partes las que pueden diseñar el régimen y delimitar la responsabilidad.

Como afirma Fleming, mediante el contrato se trata de promover una voluntaria asignación de riesgos en una sociedad que se autoregula libremente, mientras que en la responsabilidad extracontractual se asignan riesgos, de acuerdo con las valoraciones de la comunidad, por decisión de los tribunales o la ley. ${ }^{45}$

Ahora bien, en la medida que el contrato determina una órbita de riesgos previamente asumida por los contratantes ${ }^{46}$ el ámbito de la reparación está li-

44 Barros (2020), pp. 1.085-1.086.

45 Fleming (1987), p. 2. Véase también Cartwright (2019), pp. 121. Como señala ZimMERMANN (2019), p. 100: "La verdadera razón para no hacer responsable al deudor de todos los daños que derivan del incumplimiento y que causalmente están relacionados con él conforme al test de la conditio sine qua non fue anunciada ya en el siglo XVI por Molinaeus cuando discutía el caso de un carpintero que vende una caja para transportar fruta. No responde del daño que sufre el comprador que ha usado la caja para colocar vino que luego se derrama, porque "periculum tacite non suscepit". La cuestión de fondo es la asunción del riesgo de la responsabilidad. Cómo se distribuye el riesgo entre las partes no depende necesariamente de lo que una de ellas pudiera razonablemente prever, sino de lo que las partes han acordado o puede entenderse que han acordado. Es, pues, una cuestión de interpretación del contrato y de determinar qué interés servía el deber contractual que ha sido infringido".

46 Brantt (2010), pp. 86 y ss.; y, Mejías (2011), pp. 96-97. Como señala Neme (2018), pp. 112-113: "La capacidad de adaptación del contrato se extiende hasta los imprecisos terrenos del riesgo que habrán de asumir los contratantes en conformidad con el equilibrio económico del contrato. Aun en los eventos de riesgo extraordinario que no pueden resolverse a la luz de las condiciones pactadas originalmente, y que exigen, por ende, una recomposición del equilibrio del contrato, la propia estructura contractual nos orienta, pues permite establecer unas relaciones de coordinación y complementariedad entre los riesgos típicos de la actividad, las previsiones expresadas de las partes relativas a la asunción de riesgos, y, en particular, la delimitación del álea normal del contrato, las relaciones de las partes...". 
mitado a los que las partes previeron a la época de celebración del contrato, ${ }^{47}$ siendo el eje de articulación de dichos riesgos la culpa. ${ }^{48}$

En el ámbito extracontractual, por el contrario, como hemos visto, la idea de libertad soporta la noción de una idea de voluntad avalorada. Es la culpa la que expresa la idea del acto voluntario. Precisamente por ello, la distribución del riesgo social debe hacerla el tribunal, ex post, mediante el mecanismo de la culpa. ${ }^{49}$

Pero la delimitación de la responsabilidad contractual y extracontractual, fundada en el riesgo, importa, como condición, que las partes se encuentren en una genuina posición de distribuir sus riesgos. ${ }^{50}$

47 La delimitación de los daños contractuales, con claros precedentes en el Derecho romano y el antiguo Derecho francés, se introdujo en la mayor parte de los Códigos decimonónicos de la familia del francés. En principio, el Código Civil francés que, en su actual redacción, contempla la limitación de los daños reparables a los previstos a la época de celebración, en el actual artículo 1231-3. La misma delimitación de daños se incorporó en el artículo 1107 del Código Civil español de 1889; en el artículo 1228 del Codice Civile de 1865. En Latinoamérica, entre los códigos decimonónicos, consagraron una regla de limitación de daños a los previstos, el artículo 1558 del Código Civil chileno y el artículo 1616 del colombiano (que adoptó íntegramente el chileno), 1346 del Código Civil del Uruguay de 1869 (actualizado, mediante una profunda reforma, en 1995). Las codificaciones del siglo XX mantuvieron la regla de previsibilidad de daños. En Latinoamérica, particularmente, son ejemplos los artículos 345 y 346 del Código Civil de Bolivia de 1975; el Código Civil de Paraguay, de 1985, artículo 425, aunque extiende la responsabilidad dolosa a las causas mediatas. También lo hace el reciente Código Civil argentino de 2014, en el artículo 1728. Entre los instrumentos europeos, pueden mencionarse los Principios Europeos de Derecho de Contratos, artículo 9:503; el Marco Común de Referencia para el Derecho Privado Europeo, DCFR, III. 3:703. También se acoge la regla en los Principios Latinoamericanos de Derecho de Contratos, PLDC, artículo 107. Para la armonización europea, véase VAQUER (2017). En el common law, también se indemnizan, como daños, por regla general, las pérdidas económicas derivadas del incumplimiento, atendida la protección de lo que Fuller y Perdue denominan confianza esencial. Véase Fuller y Perdue (2019), pp. 37-45. Véase también, Cartwright (2019), pp. 389-392, y Burrows (2019), pp. 91-97; 105-106.

48 En efecto, la delimitación del riesgo explica que, en materia de responsabilidad contractual, los daños se limiten, como se ha visto supra, a los perjuicios previstos o que pudieron razonablemente preverse, a la época de celebración del contrato. Para un análisis de la regla de previsión de daños como eje de la distinción, véase AEDo (2018b), pp. 644 y ss.

49 En otro lugar, a propósito de la responsabilidad extracontractual, hemos asignado dicha función a la culpa. Véase nuestros trabajos AEdo (2014), pp. 714-719; AEdo (2015), pp. 811 y ss., y AEDo (2018a), pp. 342 y ss.

50 Alpa, Bessone, y Roppo (1982), p. 284. 


\section{EL PROBLEMA DE LAS FUNCIONES}

¿Contribuye el esquema de la voluntad en el diseño de las funciones de la responsabilidad civil? A nuestro juicio, una respuesta positiva se impone a esta cuestión. Para pensar esta perspectiva, siguiendo a Wilenmann, los modelos de imputación corresponden a un fundamento filosófico. Así, con particular erudición, el autor explica que el esquema tradicional de la responsabilidad, de la que bebería la responsabilidad civil, se fundaría en la libre decisión del hecho dañoso, de ahí que ésta se haga reposar en la libertad, la culpa se considere garantía del respeto de los individuos en la sociedad y en definitiva se encuentre el fundamento en la libertad de los sujetos. ${ }^{51}$

Esta perspectiva de imputación, que se basa en definitiva en la idea de libertad de los sujetos, no como reproche moral, sino como atribución de responsabilidad en función de la falla en los roles sociales que deben ser desempeñados, conduce a la afirmación de la función exclusivamente reparatoria de la responsabilidad civil. Gran parte de nuestra doctrina, sin embargo, concibe la función preventiva solo como un efecto reflejo de la función primordial de compensación en la responsabilidad civil. Así lo presenta, por ejemplo, Corral, quien señala: "Parece lógico que, desde el punto de vista psicológico, la persona que ha obrado dañinamente y en virtud de esta acción se ve conminada a soportar en su patrimonio el costo del daño causado, tratará de evitar en el futuro la conducta descuidada o dolosa que le produjo tal pérdida", agregando que lo mismo puede decirse de los demás miembros de la sociedad que son advertidos de no producir ciertos daños para evitar incurrir en desembolsos. ${ }^{52}$ Quienes han defendido esta función preventiva, ${ }^{53}$ negando su función punitiva y repudiando la

51 Véase WiLenManN (2017), pp. 281 y ss.

52 Por todos, Corral (2004), pp. 66-67. En un sentido similar se pronuncia, en el derecho comparado, DíEz- Picazo (1999), p. 47, quien admite que pueda haber una prevención, tanto general, como especial, como un impulso psicológico para el ciudadano que trata de evitar las consecuencias desfavorables de la norma; y, la prevención especial, en cuanto se influye en las acciones futuras de una persona.

53 Los afanes preventivos ya nos han sido señalados por la dogmática penal. Se trata de un camino que ya se ha transitado, en el que la culpa sufrió ataques desde el último tercio del siglo XX, impulsando la disolución del juicio de reproche por razones preventivas, lo que condujo a una parte de la dogmática, como indica Fernández, a articular un Derecho penal no basado en el libre albedrío, desde que la libertad resulta un elemento empíricamente indemostrable. Véase Fernández (2006), p. 38. Por citar un ejemplo, BARToli (2005), p. 59, estima que la culpa no puede fundarse en la posibilidad de querer diversamente, pues dicha voluntad es indemostrada, más precisamente, la libertad de querer es indemostrable, pero además el autor reprocha que la libertad para querer diversamente no entrega un valor, no es un parámetro, un criterio, sino un dato de hecho, en otros términos, que el poder querer no 
importación de los punitive damages, son las visiones provenientes del análisis económico del Derecho. ${ }^{54}$

Nuestra doctrina considera, en efecto, idea que compartimos, que el principio de justicia correctiva puede justificar tanto un régimen de responsabilidad estricta como uno de culpa ${ }^{55}$ Pero también se ha sostenido, y con razón, que aunque este enfoque es correcto es incompleto, por cuanto el sistema requiere de la justicia distributiva para ser comprendido. ${ }^{56} \mathrm{Y}$, sin que pueda ahondarse en este lugar, la mirada distributiva puede dar lugar a una comprensión más amplia de las funciones de la responsabilidad civil y al empleo de determinadas herramientas, tanto para la prevención ${ }^{57}$ como para la punición, incluido el daño moral..$^{58}$

puede ser utilizado como criterio al interior de un juicio de reproche o incluso al interior de una concepción normativa de la culpa, porque no es un parámetro capaz de fundar un juicio valorativo, sino que representa una realidad empírica, a la que se le agrega un atributo de valor opinable.

54 Para el análisis económico del derecho, sus escuelas y propuesta de prevención, AEdo (2018a), pp. 293 y ss. Estas finalidades se cumplen, según Díez-Picazo, de acuerdo a algunos criterios que han sido elaborados por los analistas económicos del Derecho: a) la fórmula elaborada por el juez federal norteamericano Learned Hand, según quien era posible acuñar una fórmula algebraica para determinar la concurrencia de responsabilidad, así se afirma que esta deberá declararse si los costes de prevención son inferiores al daño reclamado: “... si a la probabilidad que se le llama $P$, al daño $D$ y al costo de las medidas de prevención $C$, la responsabilidad dependerá de que C sea menor que D multiplicado por P"; b) la figura del cheapest cost avoider, según el cual en determinados casos la responsabilidad puede resolverse atendiendo quién habría podido evitar el daño con el coste menor. Díez-Picazo (1999), pp. 210-212.

55 Véase Barros (2020), p. 312. Como afirma Pino (2013), p. 111: "La conclusión de Enrique Barros respecto a que tanto la responsabilidad por culpa como estricta atienden a exigencias de justicia correctiva me parece acertada. Jules L. Coleman también llega a una conclusión similar. Sostiene que en términos generales, el derecho de daños es fundamentalmente responsabilidad estricta, con independencia de si el agente actuó con culpa o no".

56 Para el desarrollo del problema del fundamento de la responsabilidad civil, véase Aedo (2019).

57 Para el problema de la función preventiva de la responsabilidad civil, separada de una punitiva, véase AEDo (2018a), pp. 266 y ss.

58 Para las manifestaciones de la función punitiva, Aedo (2006), pp. 43-45. Para el caso del daño moral, con carácter general, véase el trabajo de BARRIENTOS (2007), pp. 51 y ss. El autor no comparte la tesis de la función punitiva asociada a la figura y defiende una función estrictamente resarcitoria. El empleo del daño moral, para efectos de punir, lo ha defendido, mediante la introducción de criterios que implican una valoración del comportamiento del ofensor en términos de pena, por ejemplo, PINo (2018), pp. 496 y ss. 
Precisamente, un enfoque de justicia distributiva e, incluso, una noción amplia de justicia correctiva corresponderían mejor con lo que Wilenmann denomina como modelo de responsabilidad débil, el que acoge la distribución de costos como función principal del régimen, en la medida que el sistema de imputación ya no reposa necesariamente en la decisión libre del sujeto, como la responsabilidad estricta. ${ }^{59}$

A partir de esta última lectura, podrían seguir planteándose problemas asociados a las funciones, como la responsabilidad de las personas jurídicas, pero estas consideraciones escaparían a las reflexiones que quieren expresarse en este trabajo.

\section{CONCLUSIONES}

La responsabilidad civil, pese a sus propósitos prácticos y su eventual disociación con la idea directa de castigo, está fuertemente enraizada con nuestras nociones de reproche, pre-jurídicas, como la culpa, cuyas proyecciones en la conciencia humana profunda son innegables, y de las que el jurista solo puede hacerse cargo según el objetivo, u objetivos, de la responsabilidad. ${ }^{60}$

La atribución de un daño, más allá del carácter de la culpa, lleva implícita la idea de libertad. No estoy convencido de que la sola existencia de una culpa objetiva (como desviación de un patrón de comportamiento) sea suficiente para estimar que estamos en el caso de un modelo de responsabilidad débil, por dos razones.

Por un lado, la estructura de la culpa jurídica (al menos en el campo de la responsabilidad civil) y aquella de la moral coinciden, pero operan en radios diversos. ${ }^{61}$ La segunda es que, como hemos visto, nuestra concepción de culpa es ajena a la configuración de la responsabilidad, a partir de una mens rea. No se trata, por consiguiente, de un actus non facit reum nisi mens sit rea, sino de un desajuste de las expectativas sociales, traducidas en un estándar de comportamiento relativo a otros. Solo en esta dimensión de la culpa es posible entender la idea de voluntad y por qué esta no puede equipararse a la voluntad propia de los actos jurídicos.

59 WilenMann (2017), pp. 281 y ss.

60 Para los fundamentos de esta afirmación, véase Aedo (2020), pp. 279 y ss.

61 Aedo (2018a), pp. 251 y ss.; Aedo (2020), pp. 274 y ss. 
Ahora bien, a pesar de eso, la culpa, en tanto mecanismo de distribución de riesgo social, para actividades de riesgo ordinario, se conecta muy bien con los fundamentos morales de la responsabilidad civil, tanto para aquellos que fundan una responsabilidad extracontractual en lo que se ha denominado la teoría de la reciprocidad, sustentada por Fletcher, ${ }^{62}$ como aquellos que defienden la culpa, fundándola exclusivamente en la justicia correctiva, como Weinrib, ${ }^{63} \mathrm{o}$ aquellos que, como Papayannis, consideran que la justicia distributiva permite la justificación, tanto de un régimen de culpa, como estricto (para actividades peligrosas); ${ }^{64}$

62 Fletcher (1972), pp. 537 y ss., afirma que es el riesgo el principio que funda la responsabilidad civil. En la vida social, Fletcher sostiene que cada miembro de la sociedad tolera o debe tolerar un margen de riesgo derivado de las actuaciones ajenas y a la luz de la propia producción de riesgos frente a los demás. Si quien se embarca de una actividad de riesgo ordinario no adopta los cuidados razonables, y ello se materializa en un perjuicio, entonces ha generado un riesgo no recíproco que debe ser indemnizado. Para las actividades de riesgo anormal o peligrosas, el riesgo recíproco no se aplica y, por tanto, no puede haber balance de riesgos, respondiéndose de los daños conforme a la responsabilidad estricta. Aunque con otra perspectiva muy distinta, enfocando el problema sobre la naturaleza del deber de cuidado, una mirada bilateral al problema de responsabilidad se puede encontrar en la teoría de las normas diádicas de ZIPURSKY (1998), pp. 67-70; ZIPURSKY (2013), pp. 233-234, que además se relaciona muy bien con el fin de protección de la norma, como principio causal.

63 WeINRIB (2013), p. 332, afirma que el mérito de un régimen de culpa se encuentra en la descripción del riesgo que debe entenderse como ilícito o desaprobado, del mismo modo que la relación de causalidad conecta la culpa del demandado con el daño experimentado por el demandante. Agrega: "Sin embargo, cuando el demandante que sufre el perjuicio es un miembro de la clase de personas que el demandado puso en riesgo, y es la clase de perjuicio o accidente mediante el debido cuidado, entonces la ilicitud de la acción del demandado y el perjuicio del demandante se refieren a la misma clase de riesgo. En estas circunstancias, la secuencia desde la creación de un riesgo irrazonable por el demandado a la materialización de este riesgo en un perjuicio al demandante constituye la misma injusticia para ambas partes". Con todo, si la culpa determina un ámbito de riesgo desaprobado, no parece tan simple distinguir la atribución de la culpa, a menos que la causalidad sea un puro problema fáctico, cuestión que conocidamente no ocurre en la aproximación moderna de la imputación causal, especialmente pensando en las omisiones. Para ver de qué manera las omisiones fallan en la descripción de la estructura de la voluntad, véase HART (2019), pp. 117-119. Para un análisis de las confluencias entre culpa y causalidad, especialmente la creación de riesgo no permitido, Aedo (2018a), pp. 415 y ss.

64 Papayannis (2012), p. 75, indica: "El propósito de la responsabilidad extracontractual tiene que ver con la rectificación de las interacciones injustas y, por lo tanto, con la implementación de la justicia correctiva. Únicamente apelando a este principio es posible hacer inteligible el discurso jurídico de los participantes preservando el sentido que para ellos tienen las doctrinas principales del derecho de daños y el contenido de los conceptos que utilizan para darles forma". Pero, como enfatiza el mismo PAPAYANnis (2013), pp. 400-401, para que opere la justicia correctiva, es necesario que opere antes la justicia distributiva. Y, según el autor, lo que distribuyen son derechos y deberes de indemnidad. En dicha distribución, caben las reglas de responsabilidad por culpa y las de responsabilidad estricta: "Dado que 
e, incluso, en quienes han sugerido una suerte de responsabilidad por el resultado de nuestra agencia, como Honoré65 o Perry, ${ }^{66}$ no asignan una función muy distinta al modelo de asignación de riesgos que cumple la culpa.

cada regla tiene efectos distributivos distintos, ellas establecen distintos contenidos para los derechos de indemnidad de cada una de las partes. La regla de responsabilidad por culpa implica un derecho a no ser dañado por conductas negligentes o dolosas a otras personas, y un correlativo deber de no dañar de ese mismo modo; la regla de responsabilidad objetiva, por su parte, supone un derecho a no ser dañado por conductas inusualmente peligrosas". Esta idea, ahora atendida desde la justicia distributiva, que la incorpora, puede conectarse perfectamente con que la culpa y la responsabilidad estricta operan como mecanismo de distribución de riesgos sociales.

65 Honoré (1997), pp. 76 ss., quien nos explica que para justificar un régimen de responsabilidad no basta con mostrar que el Estado adopta un mecanismo para prevenir los comportamientos indeseables y proteger los derechos vulnerados, otorgando la compensación por los perjuicios. Hay algo más, pues el sistema de responsabilidad por daños encuentra fundamento en la vieja idea de la justicia correctiva, la que se desenvuelve en una óptica relacional, que requiere la presencia de un dañador que ha inferido un perjuicio a un tercero. La exigencia de la culpa como criterio exclusivo de la justicia correctiva no es aceptada por Honoré, quien piensa que de este modo se reduce el concepto de ella. Para Honoré, la responsabilidad por el resultado supone una concepción amplia de la justicia correctiva, aunque luego afirme que la justicia distributiva es la que permite fundamentar una responsabilidad estricta y estime que la responsabilidad surge de una combinación de ambas. En la lectura de HoNORÉ (2013), pp. 128-129, es también la distribución de riesgos de la responsabilidad civil la que abre la puerta a la responsabilidad por los resultados, agregando, como hemos propuesto, que tanto un sistema de culpa, como de responsabilidad estricta, cumplen con dicha distribución, aunque de modo distinto. Honoré considera que tanto la responsabilidad estricta como la responsabilidad por culpa forman parte del género de la responsabilidad por el resultado. Honoré piensa que los sistemas de responsabilidad terminan asignando una responsabilidad por el resultado, por cuanto nuestras apuestas o elecciones de nuestras conductas derivan de nuestras experiencias de vida con los demás. Sabemos, de este modo, que elegir tal o cual acción podría importar una desaprobación o descrédito de los otros o, por el contrario, traducirse en la evitación de los perjuicios, siendo en definitiva la sociedad la que asigna las consecuencias de los resultados. Pero, para que sea justa, dicha asignación hecha por la sociedad debe ser imparcial, recíproca y por un período determinado. Véase también, HONORÉ (2002): 25-31.

66 Según Perry, la idea de la responsabilidad por el resultado se encuentra completamente en contradicción con que dicha responsabilidad está íntimamente ligada a la persona, pues según este autor la personalidad supone una capacidad de auto-reflexión y cognición, e implica un cúmulo de experiencias y de elección, de modo que la responsabilidad por el resultado dice relación con nuestras elecciones. La pretendida responsabilidad por el resultado, piensa este autor, envuelve una evaluación de las elecciones del sujeto. Agrega que la evaluación ex post no es solamente una proyección retrospectiva de la conducta del agente y del resultado producido por su acción, porque también es materia de ella determinar si el agente puede justificar su acción o si ha existido una equivocación de su parte. En suma, como agente, no solo se producen consecuencias, pues los seres humanos poseemos consciencia de nosotros mismos como seres capaces de hacer una diferencia en el mundo circundante. Perry (1992): 
La idea de libertad, subyacente en el esquema de conducta, permite explicar, del modo propuesto, tanto la delimitación de regímenes (no en el plano dogmático, sino en el de sus fundamentos), así como introducir de mejor manera la discusión de las funciones. No obstante, la idea de voluntad tiene pendiente la conciliación de su estructura, como ha dicho Hart, con las omisiones, de ahí el conflicto que surge con estas para la configuración de la causalidad y el auxilio que brinda la culpa en su construcción. ${ }^{67}$

465-466; 491-492; 494. Sobre el rol de la previsibilidad en la evaluación de riesgos, véase PERRY (1988): 162-164.

67 Véase, sobre este problema, AEDo (2017b), pp. 514-515. 


\section{BIBLIOGRAFÍA CITADA}

AdkIns, Arthur W.H. (1960): Merit and responsibility. A study in Greek Values (Oxford, Clarendon Press).

Aedo Barrena, Cristián (2006): Responsabilidad Extracontractual (Santiago, Librotecnia):

Aedo Barrena, Cristián (2009): "Los requisitos de la lex Aquilia, con especial referencia al daño. Lecturas desde las distintas teorías sobre el capítulo tercero", Ius et Praxis, vol. 15, núm. 1.

Aedo Barrena, Cristián (2011): “La interpretación jurisprudencial extensiva a los verbos rectores de la lex Aquilia de damno", Ius et Praxis, vol. 17, núm. 1.

Aedo Barrena, Cristian (2014a): "El problema del concepto de la culpa en la lex Aquilia. Una mirada funcional", Revista de Derecho Universidad Austral de Chile, vol. XXVII, núm. 1.

Aedo Barrena, Cristián (2014b): "El concepto normativo de la negligencia como criterio de distribución de riesgos. Un análisis jurisprudencial", Revista Chilena de Derecho, vol. 41, núm. 2.

Aedo Barrena, Cristián (2015): “La culpa como criterio de distribución de riesgos sociales ¿hay en la negligenceuna infracción a un deber de cuidado?”, en Vidal Olivares, Álvaro, Severin Fuster, Gonzalo y Mejías Alonzo, Claudia (editores), Estudios de Derecho Civil X (Santiago, Thomson Reuters).

Aedo Barrena, Cristián (2017a): “¿Siguió el Código Civil francés el pensamiento de Domat en materia de culpa (faute) extracontractual?", Revista Chilena de Derecho, vol. 44, núm. 3.

Aedo Barrena, Cristián (2017b): “La creación de riesgos no permitidos en la imputación objetiva, ¿un problema de culpa? Hacia un sistema funcional”, en Corral Talciani, Hernán y Manterola Domínguez, Pablo (editores), Estudios de Derecho Civil XII (Santiago, Thomson Reuters). 
Aedo Barrena, Cristian (2018a): Culpa aquiliana. Una conjunción de aspectos históricos y dogmáticos (Santiago, Thomson Reuters).

Aedo Barrena, Cristian (2018b): "La delimitación de la responsabilidad contractual y la aquiliana y su incidencia en la reparación del daño moral". VIDAL Olivares, Álvaro (director) y SEVERIN Fuster, Gonzalo (editor), Estudio de Derecho de Contratos. En Homenaje a Antonio Manuel Morales Moreno (Santiago, Thomson Reuters).

Aedo Barrena, Cristian (2018c): “El derecho romano en el pensamiento jurídico y en el método de Jean Domat, con especial referencia a la responsabilidad civil y a la faute", GuzMÁn Brito, Alejandro (director), Libro de amigo dedicado al profesor Carlos Salinas (Santiago, Thomson Reuters).

Aedo Barrena, Cristian (2019): "La culpa como fundamento de la responsabilidad extracontractual”, Pereira Fredes, Esteban (editor), Fundamentos Filosóficos del Derecho Civil Chileno (Santiago, Rubicon Editores).

Aedo Barrena, Cristian (2020): Fundamentos filosóficos de la culpa jurídica (Bogotá, Universidad del Externado).

Ahrens, Enrique (2004): Derecho natural o Filosofía del Derecho (trad. de la $6^{a}$ edición original por Pedro Rodríguez Hortelano y Mariano Ricardo de Asensi. Pamplona. Analecta Editorial, reimpresión de la $4^{\mathrm{a}}$ edición española de 1889).

Alpa, Guido y Bessone, Mario (1976): La responsabilità civile: illecito per colpa, rischio d'impresa, assicurazione (Milano, Giuffrè).

Alpa, Guido; Bessone, Mario; Roppo, Enzo (1982): Rischio contrattuale e autonomía privata (Napoli, Jovene Editore).

Antunes Varela, Joao de Matos (1996): Das obrigaçòes em geral (Coimbra, Editorial Coimbra, 9a edición, vol. I).

BAdosa Coll, Ferrán (1987): La diligencia y la culpa del deudor en la obligación civil (Bologna. Publicaciones del Real Colegio de España).

BARCELlONA, Mario (2001): "La buona fede e il controllo giudiziale del contratto", en Mazzamuto, Salvatore (a cura di): Il contrato e le tutele prospettive di Diritto europeo (Torino, Giappichelli). 
BARRIENTOS ZAMORANo, Marcelo (2007): El resarcimiento por daño moral en España y Europa (Salamanca, Ratio Legis).

Barros Bourie, Enrique (2020): Tratado de responsabilidad Civil Extracontractual (Santiago, Editorial Jurídica de Chile, $2^{\text {a }}$ edición).

BARTOLI, Roberto (2005): Colpevolezza: tra personalismo e prevenzione (Torino. Giappichelli).

Bello, Andrés (1981): Obras Completas, vol. XVII: Derecho Romano (Caracas, La Casa de Bello).

Bello Reguera, Eduardo (1993): Estudio preliminar y notas al Discurso del Método (Barcelona, Atalaya).

Bernad MaInAR, Rafael (2019): La Contratación Civil, una fiel expresión de la patrimonialidad del Derecho Civil (Madrid, Thomson Reuters-Aranzadi).

Bianca, Massimo (2018): Diritto Civil, t. V: La responsabilità (Milano, Giuffrè, ristampa $2^{\mathrm{a}}$ edizione).

BrantT Zumarán, María Graciela (2010): El caso fortuito y su incidencia en el Derecho de la responsabilidad civil contractual (Santiago, AbeledoPerrot).

BRIAN, Isabelle (2013): "El jansenismo. Entre la seducción rigorista y la mentalidad de oposición", Corbin, Alain (director): Historia del Cristianismo (Barcelona, Ariel).

BuERES, Alberto (1996): "El daño injusto y la licitud e ilicitud de la conducta", en Trigo Represas, Félix y Stiglitz, Rubén (coordinadores): Derecho de Daños. Homenaje en honor al profesor Jorge Mosset Iturraspe. Primera parte (Buenos Aires, La Rocca, $1^{\text {a }}$ reimpresión).

Burrows, Andrew (2019): Remedies for torts, breach of contract, and equitable wrongs (Oxford, Oxford University Press, $4^{\mathrm{a}}$ edition).

Busnelli, Francesco (2005): "Giustizia conttratuale", Roma e America. Diritto Romano Comune, núms. 19-20.

Carpintero Benítez, Francisco (1989): La Cabeza de Jano (Cádiz, Servicio de Publicaciones Universidad de Cádiz). 
Carpintero Benítez, Francisco (2000): Historia breve del Derecho Natural (Madrid, Colex).

CARPintero Benítez, Francisco (2004): Justicia y Ley natural: Tomás de Aquino y los otros escolásticos (Madrid, Servicio de Publicaciones, Facultad de Derecho, Universidad Complutense de Madrid).

CARTWRIGHT, John (2019): Introducción al Derecho inglés de los contratos (traducción Juan Pablo Murga Fernández, Madrid, Thomson Reuters-Aranzadi).

CASSIRER, Ernst (2013): Filosofía de la Ilustración (traducción de Eugenio Ímaz, México D.F., Fondo de Cultura Económica, $8^{\mathrm{a}}$ reimpresión de la $3^{\mathrm{a}}$ edición).

Corral Talciani, Hernán (2004): Lecciones de responsabilidad civil extracontractual (Santiago, Editorial Jurídica de Chile).

Copleston, Frederick (2017): Historia de la Filosofia. Vol. 2: de la escolástica al empirismo. t. IV: de Descartes a Leibniz (traducción de Juan Carlos García Borrón, Barcelona, Planeta, $6^{\mathrm{a}}$ reimpresión de la $1^{\mathrm{a}}$ edición).

CUYACIO, Jacobo (1585): Institutiones Iustiniani (Paris, Sebastianum Nivelum).

De Aquino, Tomás (1963): Summa Theologiae, Secunda Secundae (Madrid, Biblioteca de Autores Cristianos, $3^{\mathrm{a}}$ edición).

De Aquino, Tomás (1990): Suma de Teología (trad. de Emilio García Estébanez, Madrid, Biblioteca de Autores Cristianos).

De Castro y Bravo, Federico (1967): El negocio jurídico (Madrid, Instituto Nacional de Estudios Jurídicos).

De Soto, Domingo (1968): De Iustitia et de Iure. De la justicia y del Derecho en diez libros (trad. y versión castellana por Marcelino González Ordóñez, Madrid, Instituto de Estudios Políticos).

DíAz Ardila, Jorge Aurelio (1995-1996): "Y sí me equivoco y peco", Universitas Philosophica, núms. 25-26.

Dítz-Picazo, Luis (1999): Derecho de Daños (Madrid, Civitas).

DiHLE, Albrecht (1982): The theory of will in classical antiquity (Berkeley-Los Angeles-London, University of California Press). 
Di Majo, Adolfo (2005a): "Il linguaggio dei rimedi”, Europa e diritto privato, núm. 2.

Di MAJo, Adolfo (2005b): "Tutela risarcitoria: alla ricerca di una tipologia", Revista di Diritto Civile, vol. LI.

Di MAJo, Adolfo (2006): “Adempimento e risarcimento nella prospettiva dei rimedi", VV.AA., Il diritto delle obbligazioni e dei contratti: verso una riforma? (Milano, Cedam).

Dopazo Gallego, Antonio (2019): Descartes. Un filósofo más allá de toda duda (Barcelona, Edapp).

DraPKIN, Abraham (1943): Relación de causalidad y delito (Santiago, Editorial Cruz del Sur).

Engelmann, Woldemar (1965): Die Schuldlehre der Postglossatoren und Ihre Fortenwicklung: eine historisch-dogmatische Darstellung der kriminellen Schuldlehre der italienischen Juristen des Mittelalters seit Accursius (Aalen, Scientia).

FeEnSTRA, Robert (1973): "L' influence de la scolastique espagnole sur Grotius en droit privé: quelques expériences dans des questions de fond et de forme, concernant notamment les doctrines de l'erreur et de l'enrichissement sans cause", en Grossi, Paolo (a cura di): La seconda scolastica nella formazione del Diritto privato moderno (Milano, Giuffrè).

FeEnStRA, Robert (1975): Grocio y el Derecho privado europeo (trad. de Ana María Barrero, $A H D E$, vol. XLV).

FERnÁNDEZ GonzÁLEz, María Begoña (2012): “Incumplimiento total”, en O'CALlAGHAN MuÑoz, Xavier (coordinador): Cumplimiento e incumplimiento (Madrid, Editorial Universitaria Ramón Areces).

FERnÁnDEZ, Gonzalo D. (2006): "Presentación: La cuestión de la libertad de voluntad en el derrotero de la teoría de la culpabilidad" al libro La teoría de la libertad de la voluntad en la actual doctrina filosófica del Derecho penal, de Karl Engisch (trad. de la edición alemana de 1965 por José Luis Guzmán Dálbora, Montevideo, Buenos Aires, Editorial B de F.).

Fleming, J. G. (1987): The Law of Torts (Sidney, The Law Book Company, 7 edition). 
FLETCHER, George (1972): "Fairness and Utility in Tort Theory", Harvard Law Review, vol. 85.

FLUME, WeRner (1967): El negocio jurídico (traducción de la 4a edición alemana por José María Miquel González y Esther Gómez Calle, Madrid, Fundación Cultural del Notariado).

Filomusi Guelfi, Francesco (1949): "La codifizione civile e le idee moderne che ad essa si riferiscono", en Del Vecchio, Giorgio (a cura di): Lezioni e saggi di Philosophy del diritto (Milano, Giuffrè).

Fuller, Lon y Perdue, William (2019): Indemnización de los daños contractuales y protección de confianza (traducción de Carlos Augusto Gonzáles, Santiago, Olejnik).

GAUDEMET, Jean (1991): "Il diritto canonico nella storia della cultura giuridica europea”, en AA.VV. Scienza giuridica e diritto canonico (Torino, Giappichelli).

Gómez Calle, Esther (2018): Desequilibrio contractual y tutela del contratante débil (Madrid, Thomson Reuters-Aranzadi).

GordLey, James (1992): The Philosophical origins of modern contract doctrine (Oxford, Clarendon Press).

GordLey, James (1994): "Myths of the French Civil Code", The American Journal of Comparative Law, vol. XLII.

Guzmán Brito, Alejandro (2004): "La sistemática del Derecho Privado en el "De iure belli ac pacis" de Hugo Grotius", Revista de Estudios Histórico Jurídicos, vol. 26.

HALPÉRIN, Jean Louis (1992): L'impossible Code Civil (Paris, PUF).

HART, H.L.A. (2019): Castigo y Responsabilidad. Ensayos de filosofia del Derecho (traducción de Jacobo Barja de Quiroga y León García-Comendador Alonso, Madrid, Marcial Pons).

HeINECCIO (1787): Elementa iuris civile secundum ordinem Institutionum (Iansonio $4^{\mathrm{a}}$ edición, Amstelodami).

Heineccio (1829): Elementos de Derecho Romano (trad. de L.A.S., Madrid, Imprenta Eusebio Aguado). 
Heisenberg, Werner (2014): “El debate entre Platón y Demócrito”, en Wilber, Ken, Cuestiones Cuánticas. Escritos místicos de los físicos más famosos del mundo (traducción Pedro de Casso, Barcelona, Kayrós, 15ª edición).

Hesphana, Antonio Manuel (2002): Cultura jurídica europea. Síntesis de un Milenio (trad. de Isabel Soler y Concepción Valera, Madrid, Tecnos).

Hinojosa y NAveros, Eduardo (1929): Los precursores españoles de Grocio, AHDE, vol. VI.

HonORÉ, Anthony (1997): “The Morality of Tort Law. Questions and Answer, en Owen, David (editor): Philosophical foundations of Tort Law (Oxford. Clarendon Paperbacks).

Honoré, Anthony (2002): Responsibility and guilt (Oxford, Portland. Hart Publishing).

Honoré, Anthony (2002): La moralidad del derecho de la responsabilidad civil extracontractual: preguntas y respuestas (traducción de Pablo Suárez).

HRUSCKA, Joachim (2005): “La imputación ordinaria y extraordinaria en Pufendorf. Sobre la historia y el significado de la diferencia entre actio libera in se y actio libera in sua causa", trad. por Nuria Pastor Muñoz. SÁNCHEZ Ostiz, Pablo (coordinador), Imputación y Derecho penal. Estudios sobre la teoría de la imputación (Madrid. Thomson-Aranzadi).

Karmy Bolton, Rodrigo (2008): "Descartes y el "fundamento místico de la razón" (introducción al problema de Dios en las Meditaciones Metafísicas)", Límite. Revista de Filosofía y Psicología, vol. 3, núm. 18.

Kolakowski, Leszek (1996): Dios no nos debe nada. Un breve comentario sobre la religión de Pascal y el espíritu del jansenismo (traducción de Susana Mactley Marín, Barcelona, Herder).

LóPEZ, Cristian (2018): “¿Qué puede decirnos la relatividad general respecto de la flecha del tiempo?”, Revista Ins. Fil. Campinas, v. 41, núm. 3

Maiorca, Sergio (1981): Il Contratto. Profili della disciplina generale (Torino, Giapichelli).

MASI, Roberto (1963): "El pecado filosófico", en AA.VV. El pecado en la filosofía moderna (trad. de José Luis Martín, Madrid, Ediciones Rialp). 
Mejías Alonso, Claudia (2011): El incumplimiento resolutorio en el Código Civil (Santiago, AbeledoPerrot-LegalPublishing).

MiLo, Ronald D. (1966): Aristotle on Practical Knowledge and Weakness of Will (La Haya, Mouton \& CO).

Morales Moreno, Antonio Manuel (2006): La modernización del Derecho de obligaciones (Madrid, Thomson-Civitas).

Náquira Riveros, Jaime (1998): Derecho Penal. Teoría del delito. Tomo I (Santiago, Mc Graw Hill).

Neme Villarreal, Martha Lucía (2018): "El contrato, una estructura capaz de contener los elementos del desarrollo", en Ella misma (coordinadora), Autonomía Privada. Perspectivas del Derecho Contemporáneo (Bogotá, Ediciones Universidad Externado).

Owen, David (1997): "Philosophical Foundations of guilt in Tort Law", en El mismo (editor), Philosophical foundations of Tort Law (Oxford, Clarendon Paperbacks).

PANTAleón Prieto, Fernando (2010): "El sistema de responsabilidad contractual (materiales para un debate)", en Sото Coaguila, Carlos (coordinador), Incumplimiento contractual. Acciones del acreedor contra el deudor (Buenos Aires, La Ley).

PAPAYANNIS, Diego (2012): “Teorías sustantivas de la responsabilidad extracontractual y la relevancia de la metodología", Isonomía núm. 37.

Papayannis, Diego (2013): "Derechos y deberes de indemnidad", en Bernal Pulido, Carlos y Fabra Zamora, Jorge (editores), La filosofía de la responsabilidad civil (Bogotá, Universidad del Externado).

PAPAYANnIS, Diego (2014): Comprensión y justificación de la responsabilidad extracontractual (Madrid, Marcial Pons).

Perry, Stephen R. (1988): “The impossibility of General Strict liability”, Canadian Journal of Law and Jurisprudence, núm. 1.

Perry, Stephen R. (1992): “The Moral Foundations of Tort Law”, Iowa Law Review, núm. 77. 
PINO EMHART, Alberto (2011): “Justicia distributiva, responsabilidad civil y terremotos", Derecho y Justicia, núm. 1.

Pino EmHarT, Alberto (2013): "Entre reparación y distribución: la responsabilidad civil extracontractual como mecanismo de distribución de infortunio", Revista Chilena de Derecho Privado, núm. 21.

Pino EmHarT, Alberto (2018): "La situación económica de las partes y la avaluación del daño moral. Al rescate de una vieja tesis", BAHAMONDES OYARZúN, Claudia, Etcheberry Court, Leonor y Pizarro Wilson, Carlos (editores), Estudios de Derecho Civil XIII (Santiago, Thomson Reuters).

RIPERT, Georges (1949): La règle morale dans les obligations civiles (Paris, LGDJ, $4^{\text {a }}$ edición).

RiPert, Georges y Boulagner, Jean (1965): Tratado de Derecho Civil, según el Tratado de Planiol, t. IV: Las obligaciones (2 ${ }^{a}$ parte) (trad. de Delia García Daireaux, Buenos Aires, La Ley).

Rodríguez Grez, Pablo (1999): Responsabilidad extracontractual (Santiago, Editorial Jurídica de Chile).

Roxin, Claus (1997): Derecho Penal. Parte general, t. I: Fundamentos. La estructura de la teoría del delito (trad. de la $2^{\mathrm{a}}$ edición alemana por Diego Luzón Peña, Miguel Díaz y García Conlledo y Javier de Vicente Remesal, Madrid, Civitas).

Salvador Coderch, Pablo y Castiñeira Palou, María Teresa (1997): Prevenir y castigar. Libertad de información y expresión, tutela del honor y funciones del Derecho de daños (Barcelona, Marcial Pons).

SÁNCHEZ DE LA TORRE, Ángel (1962): Los griegos y el derecho natural (Madrid, Tecnos).

SAN Martín Neira, Lilian (2018): "La imputabilidad o capacidad como elemento de la responsabilidad civil extracontractual. Un debate pendiente en la doctrina chilena", Ius et Praxis, vol. 24, núm. 1.

SAntos Briz, Jaime (1993): La responsabilidad civil. Derecho sustantivo y derecho procesal (Madrid, Montecorvo. $7^{\text {a }}$ Edición). 
Schulze, Reiner (2017): Ciencia jurídica y unificación del Derecho Privado Europeo (traducción de Andrés Sánchez Ramírez, Santiago, Olejnik).

TAISNE, Jean Jacques (2019): "La force obligatoire du contrat dans le nouveau droit français des obligations", en ATAZ LóPEz, Joaquín y GARCÍA PÉREZ, Carmen (coordinadores), Estudios sobre la modernización del Derecho de Obligaciones y Contratos (Madrid, Thomson Reuters-Aranzadi).

THIEME, Hans (1954): "El significado de los grandes juristas y teólogos españoles del siglo XVI para el desenvolvimiento del Derecho natural", $R D P$, vol. XXXVIII.

Trueba, Carmen (2004): Ética y tragedia en Aristóteles (Mexico D.F., Antrophos-Universidad Autónoma de México).

Vaquer Aloy, Antoni (2017): Derecho Contractual Europeo (Lima-Santiago, Ara-Olejnik).

Vial del Río, Víctor (2004): Teoría General del Acto Jurídico (Santiago, Editorial Jurídica de Chile, $5^{\text {a }}$ edición).

Vicol Ionescu, Constantin (1973): La filosofía moral de Aristóteles, t. I: La filosofia moral de Aristóteles en sus etapas evolutivas (Madrid, Consejo Superior de Investigaciones Científicas, Instituto de Filosofía Luis Vives).

VINNI, J.C., Arnoldi (1755): Intitutionum Imperialum iun quator libros (Lugduni).

WaTson, Alan (1986): La formazione del diritto civile (trad. de la edición inglesa de 1986 por Nicoletta Sarti, Bologna, Il Mulino).

WeINRIB, Ernest (2013): "Responsabilidad Extracontractual como justicia correctiva", traducción de Jorge Fabra Zamora, en Bernal Pulido, Carlos y FABRA ZAMORA, Jorge (editores), La filosofía de la responsabilidad civil (Bogotá, Universidad del Externado).

Welzel, Hans (1977): Introducción a la filosofia del derecho: derecho natural y justicia material (trad. de Felipe González Vicén, Madrid, Biblioteca Jurídica Aguilar, $2^{\text {a }}$ Press).

WiEACKer, Franz (2000): Historia del Derecho privado de la Edad Moderna (trad. de Francisco Fernández Jardón, Granada, Comares). 
WiLENMANN vON BeRnath, Javier (2017): "Concepto de responsabilidad y estructura de los modelos de imputación”, en SCHOPF OlEA, Adrián y MaRín GonzÁLEZ, Juan Carlos (editores): Lo público y lo privado en el Derecho. Estudios en homenaje al profesor Enrique Barros Bourie. Santiago (Thomson Reuters).

Wright, Richard (1992): "Substantive Corrective Justice", Iowa Law Review, núm. 77.

ZimmermanN, Reinhard (2019): La indemnización de los daños contractuales (traducción de Antoni Vaquer Aloy, Santiago, Olejnik).

ZIPURSKY, Benjamin (1998): "Rights, Wrongs and Recourse in the Law of Torts", Vanderbilt Law Review, vol. 51.

ZIPURSKY, Benjamin (2013): "La filosofía de la responsabilidad extracontractual: entre lo esotérico y lo banal", traducción de Jorge Fabra Zamora, en Bernal Pulido, Carlos y Fabra Zamora, Jorge (editores), La filosofía de la responsabilidad civil (Bogotá, Universidad del Externado). 